\title{
Development of murine model of fungal keratitis to test the antifungal efficacy of CPP conjugated Natamycin
}

\author{
Harsha Rohira $^{1}$, Sujithra Shankar ${ }^{1}$, Sushmita G Shah ${ }^{2}$, Shikha Yadav ${ }^{3}$, Aastha Jain ${ }^{4}$, Archana Chugh \\ ${ }^{1}$ Indian Institute of Technology Delhi, India \\ ${ }^{2}$ Dr CM Shah Charitable Trust-Netra Mandir, Mumbai, India \\ ${ }^{3}$ National Institute of Biologicals, Noida, India \\ ${ }^{4}$ Karlsruhe Institute of Technology, Germany
}

https://doi.org/10.17952/35EPS.2018.261

\begin{abstract}
Corneal diseases including microbial keratitis are among the major causes of visual impairment and blindness worldwide. About $50 \%$ of the total microbial keratitis is caused by various fungal species. Fusarium and Aspergillus species are found to be the most common isolates in India. Natamycin is the only FDA approved drug which is used as a first line of treatment for fungal keratitis. Drawbacks associated with the use of natamycin is poor intraocular penetration and poor water solubility. Cell penetrating peptides (CPPs) are positively charged short peptides that can translocate across the cell membrane without damaging the cell. In our study, one of the CPP i.e. TAT is used as a nanocarrier to deliver an antifungal compound, Natamycin inside the corneal cells. Recently, we have successfully shown the increased uptake of TAT dimer conjugated natamycin by corneal cells in vitro. Also, conjugated natamycin showed increased water solubility as well as antifungal activity in comparison to natamycin alone. To further investigate the antifungal activity of CPP conjugated natamycin ( $\mathrm{TAT}_{2}$-Natamycin) in vivo, we have developed a murine model of Fusarium keratitis. Immunocompromised female BALB/c mice were inoculated with different concentrations of Fusarium sp. spores and were clinically graded (0 to 4 based on the severity of the disease) after three days of infection. Based on clinical grading and microbiological examination, $10^{5}$ spores $/ 5 \mu l$ was found to be the optimum concentration for the establishment of fungal keratitis. We are currently testing $\mathrm{TAT}_{2}$ Natamycin on this animal model for its antifungal activity and the results will be compared with the marketed formulation of natamycin (Natamycin 5\% suspension).
\end{abstract}

\section{Introduction}

According to WHO, 285 million people are estimated to be visually impaired worldwide out of which 39 million are blind[1]. Among the various causes of blindness, most common causes include glaucoma, cataract and trachoma[2]. Other causes which also contribute to global blindness includes keratitis, conjunctivitis and endophthalmitis. Microbial keratitis is caused by variety of bacteria, fungi and viruses. Fungal keratitis accounts for $50 \%$ of the total microbial keratitis. In India, fungal keratitis is most commonly caused by Fusarium sp. and Aspergillus sp. [3-5]. To treat fungal keratitis caused by filamentous fungi, 5\% sterile suspension of natamycin is used which is an FDA approved first line of treatment[6]. However, due to the poor intraocular penetration ability of natamycin, its bioavailability reduces in the corneal tissue. Hence, to increase the bioavailability, corneal epithelium is debrided[7]. Despite having so much of pharmacological developments, we still lack in good ocular drug delivery system. Currently available formulations and delivery strategies are based on the use of nanocarriers. However, precorneal (solution drainage, blinking, tear film, lacrimation etc) and anatomical factors (corneal epithelium) greatly limit the drug bioavailability to the anterior segment as well as posterior segment of the eye[8]. Advancements in genomics and biotechnology have led to the discovery of short chain peptides which can translocate cargos intracellularly. These short chain peptides, termed as Cell penetrating peptides (CPPs), are the delivery vectors used for transporting various hydrophilic drugs and nucleic acid across the cells[9].

Most known CPPs are positively charged sequences which can interact with negatively charged plasma membrane. By virtue of their electrostatic interaction with the plasma membrane, they are able to deliver cargo inside the cells. Some of the common examples include $\mathrm{TAT}_{\mathrm{p}}$, Penetratin, Polyarginines, MAP, Transportan etc. Although their mechanism of entry inside the cells remains highly debated, they are still used to deliver numerous pharmaceutical molecules inside various types of cells. In our previous study[10], we have successfully shown cellular uptake as well as enhanced antifungal activity of $\mathrm{TAT}_{2}$ conjugated Natamycin in 
human corneal epithelial cell line. Now to further test the antifungal efficacy in vivo, we have developed a murine model of fungal keratitis using clinical isolate of Fusarium dimerum.

\section{Materials and Methods}

Fungal culture: The strain of fungus used in this study was Fusarium dimerum, a human clinical isolate obtained through corneal scraping. Fungus was grown on Potato Dextrose Agar (PDA) at $27^{\circ} \mathrm{C}$ for $5-7$ days and the spores were harvested in potato dextrose broth (PDB). Spores were diluted in PDB to yield concentrations of $10^{4} \mathrm{CFU} / 5 \mu \mathrm{l}, 10^{5} \mathrm{CFU} / 5 \mu \mathrm{l}$ and $4 \mathrm{X} 10^{5} \mathrm{CFU} / 5 \mu \mathrm{l}$.

Animals: Adult female inbred BALB/c mice of age 6-8 weeks were taken for the study. All animals were treated in accordance with the ARVO protocol for the Use of Animals in Ophthalmic and Vision Research. Animals were immunosuppressed with intraperitoneal injection of cyclophosphamide at $180 \mathrm{mg} / \mathrm{Kg}$ body weight 5 days, 3 days and 1 day prior to inoculation. The mice were anaesthetized with isoflurane. Scarification of cornea of the right eye of mice was done with the help of hypodermic needle under dissecting microscope. Mice were divided into 3 groups according to the inoculum concentrations. $5 \mu 1$ of the inoculum was applied on the scarified eye followed by rubbing of eyelids for about 30 seconds. After 3 days of inoculation, establishment of fungal keratitis was confirmed by Slit lamp microscopy and quantitative fungal recovery.

Clinical grading: severity of keratitis in infected animals was graded visually on Day 4 with the help of Slit Lamp Microscope and Fluorescein staining of corneal epithelial layer. Clinical grades of 0-4 were assigned on the basis of epithelial defect and corneal infiltrate (Table 1).

Quantitative fungal recovery: Enucleated eyes were individually grinded in frosted glass grinder with $0.5 \mathrm{ml}$ of PBS. Homogenate was serially diluted till 4 -fold in PDB containing $40 \mu \mathrm{g} / \mathrm{ml}$ Chloramphenicol and incubated at $30^{\circ} \mathrm{C}$ under shaking conditions. After 3 days of incubation, the last blank in the dilution series with visible fungal growth was plated on PDA plates and the colonies were counted. End point was also confirmed by sub culturing and microscopic examination.

\section{Results}

Visual scoring of keratitis: Extent of keratitis was scored on the basis of epithelial defect, corneal clouding and the size of corneal infiltrate. Clinical grading was done with the help of slit lamp microscope and fluorescein strips (Table 2). Out of 3 concentrations, $10^{4} \mathrm{CFU} / 5 \mu \mathrm{l}$ of inoculum (Group 1) was unable to establish keratitis successfully (only Grade 0 and 1). Concentrations of $10^{5} \mathrm{CFU} / 5 \mu \mathrm{l}$ (Group 2) and 4X10 ${ }^{5} \mathrm{CFU} / 5 \mu \mathrm{l}$ (Group 3) resulted in the successful establishment of keratitis (Grade 2 and 3). However, presence of peripheral hemorrhage, corneal perforation and significant inflammation were seen in the group receiving highest concentration of inoculum. Epithelial defect was confirmed by visualizing fluorescein stained cornea under blue light.

Table 1: Criteria for clinical grading of fungal keratitis

\begin{tabular}{|l|l|}
\hline Grade & Criteria \\
\hline Grade 0 & No epithelial defect or infection \\
\hline Grade 1 & Signs of epithelial defect $+/$ - infiltrate \\
\hline Grade 2 & Corneal infiltrate covering $25-50 \%$ of corneal surface \\
\hline Grade 3 & Corneal infiltrate covering $50-75 \%$ of corneal surface \\
\hline Grade 4 & Corneal infiltrate covering $>70 \%$ of corneal surface \\
\hline
\end{tabular}


Table 2: Severity of Fusarium keratitis with different inoculum size

\begin{tabular}{|c|c|c|c|c|}
\hline \multirow{3}{*}{$\begin{array}{l}\text { Inoculum Size } \\
\text { 1) } 10^{4} \mathrm{CFU} / 5 \mu \mathrm{L}\end{array}$} & \multicolumn{4}{|c|}{ Results } \\
\hline & \multirow{2}{*}{$\begin{array}{c}\text { Grade } \\
\text { Grade } 0,1\end{array}$} & Observation & \multicolumn{2}{|c|}{ Image } \\
\hline & & $\begin{array}{l}\text { No colony on PDA plate, mice were } \\
\text { comparatively healthy with slight corneal } \\
\text { epithelial defect. }\end{array}$ & Grade 0 & Grade 1 \\
\hline 2) $10^{5} \mathrm{CFU} / 5 \mu \mathrm{L}$ & Grade 2, 3 & $\begin{array}{l}\text { Fungal lawn on PDA plate, mice were weak } \\
\text { with fungal infiltrate. }\end{array}$ & & \\
\hline & & & Grade 2 & Grade 3 \\
\hline 3) $4 \times 10^{5} \mathrm{CFU} / 5 \mu \mathrm{L}$ & Grade 2, 3 & $\begin{array}{l}\text { Fungal lawn on PDA plate, mice were weak } \\
\text { with fungal infiltrate, corneal perforations and } \\
\text { peripheral hemorrhage. }\end{array}$ & Grade 2 & Grade 3 \\
\hline
\end{tabular}

Quantitative fungal recovery: Fusarium $s p$. infected eyes were enucleated and the homogenate was serially diluted in PDB containing chloramphenicol. After 3 days of inoculation at $30^{\circ} \mathrm{C}$ under shaking conditions, visible growth was seen in all three groups. No fungal colonies on PDA plates were seen in case of group 1 whereas fungal lawn was observed in both group 2 and group 3. Presence of fungal spores in broth was also confirmed microscopically (Figure 1).
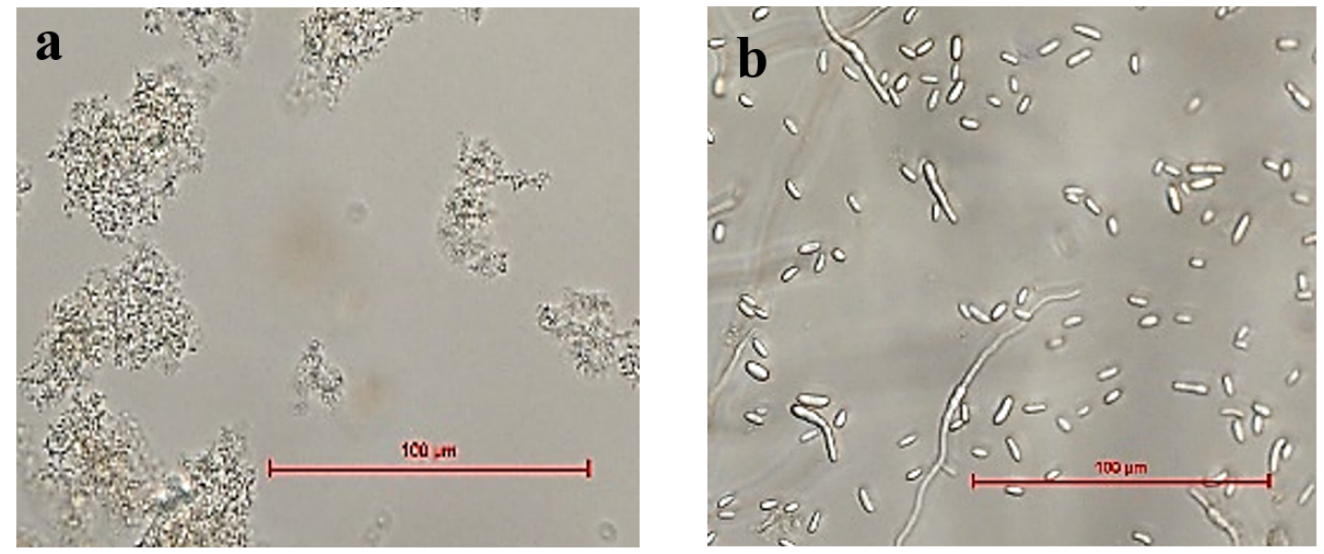

Figure 1: Microscopic images of wet mount prepared from serially diluted cultures (a) control eye (b) Fusarium sp. Spores and mycelia observed in culture obtained from the infected eye.

\section{Conclusions}

For murine model, successful establishment of infection was seen in concentrations $10^{5} \mathrm{CFU} / 5 \mu \mathrm{L}$ and $4 \times 10^{5}$ $\mathrm{CFU} / 5 \mu \mathrm{L}$ after immunosuppression with cyclophosphamide. However, animals infected with highest concentration of fusarium spores showed corneal perforations resulting in peripheral hemorrhage. Establishment of infection was also confirmed by microscopic analysis of fungal spores in ocular homogenate. No fungal spore was detected in animals infected with lowest concentration of fusarium spores. Based on the above observations, concentration of $10^{5} \mathrm{CFU} / 5 \mu \mathrm{L}$ was selected as the effective inoculum size to be used in further studies.

\section{References}

1. WHO | Visual impairment and blindness. at <http://www.who.int/mediacentre/factsheets/fs282/en/>

2. Roodhooft, J. M. J. Leading causes of blindness worldwide. Bull. Soc. belge Ophtalmol. 283, 19-25 (2002).

3. Tuft, S. J. Suppurative keratitis. Br. J. Ophthalmol. 87, 127 (2003).

4. Rajappa, S. A. \& Shaji, J. A Clinical Study of Suppurative Keratitis. Int. J. Biomed. Res. 6, 869-873 (2015).

5. Gopinathan, U. et al. The epidemiological features and laboratory results of fungal keratitis: a 10-year review at a referral eye care center in South India. Cornea 21, 555-559 (2002).

6. Ansari, Z., Miller, D. \& Galor, A. Current Thoughts in Fungal Keratitis: Diagnosis and Treatment. Curr. 
Fungal Infect. Rep. 7, 209-218 (2013).

7. M. O’ Day, D., Steven Head, W., D. Robinson, R. \& A. Clanton, J. Corneal penetration of topical amphotericin B and natamycin. Curr. Eye Res. 5, 877-882 (1986).

8. Gaudana, R., Ananthula, H. K., Parenky, A. \& Mitra, A. K. Ocular drug delivery. AAPS J. 12, 348-360 (2010).

9. Stewart, K. M., Horton, K. L. \& Kelley, S. O. Cell-penetrating peptides as delivery vehicles for biology and medicine. Org. Biomol. Chem. 6, 2242-2255 (2008).

10. Jain, A., Shah, S. G. \& Chugh, A. Cell penetratingpeptides as efficient nanocarriers for delivery of antifungal compound, natamycin for the treatment of fungal keratitis. Pharm. Res. 32, 1920-1930 (2015). 